\title{
Imunoistoquímica: detecção de microcistina em tilápia exposta ao extrato de Microcystis aeruginosa (Cyanobacteria)
}

\section{Imunohistochemistry: detection of microcystin in tilápia exposed to Microcystis aeruginosa (Cyanobacteria) extract}

\author{
Márcia Kamogae ${ }^{1}$; Elisabete Hiromi Hashimoto ${ }^{1}$; Ana Paula Millet ${ }^{1}$; Aniê Ieda \\ Francabandiera ${ }^{1}$; Camilla Guiotti de Pádua ${ }^{1}$; Ana Paula Frederico Rodrigues \\ Loureiro Bracarense ${ }^{1}$; Maria do Carmo Bittencourt-Oliveira ${ }^{2}$; Ilce Mara de Syllos \\ Colus $^{1}$; Eiko Nakagawa Itano ${ }^{1}$; Ossamu Kawamura ${ }^{3}$; Tomoaki Tsutsumi ${ }^{4}$; \\ Satoshi Nagata ${ }^{5}$ Ken-ichi Harada ${ }^{6}$ Y Yoshio Ueno ${ }^{5}$; Elisa Yoko Hirooka ${ }^{1 *}$
}

\section{Resumo}

\begin{abstract}
A deterioração da qualidade de água pela piscicultura associa-se à eutrofização, com florescimento de cianobactérias. Microcystis aeruginosa destaca-se como principal produtora de microcistinas (MCs), grupo de hepatotoxinas com potencial promotor de tumor. No presente trabalho desenvolveu-se método imunoistoquímico para a detecção de $\mathrm{MC}$ em tilápias (Oreochromis niloticus) submetidas à injeção intraperitoneal (i.p.) ou imersão em extrato de M. aeruginosa BCCBUSP 262, empregando anticorpo monoclonal anti-MC (M8H5) e sistema polímero-peroxidase. As tilápias $(\mathrm{N}=42)$ foram submetidas a sete

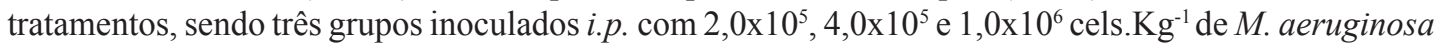
BCCBUSP 262 e quatro submetidos à imersão em diferentes concentrações do extrato da cianobactéria

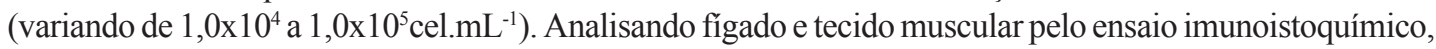
não se detectou marcação em tecido muscular. Todos os animais inoculados i.p. apresentaram marcação positiva para MC no fígado, mas em teste de imersão, apenas os expostos a maior dose $\left(1,0 \times 10^{5}\right.$ cels. $\mathrm{mL}^{-}$ ${ }^{1}$ ) apresentaram marcação positiva. Embora MC não seja detectada em tecido muscular, assim como no fígado de animais imersos em extrato de M. aeruginosa CCBUSP 262 em concentrações menores que $1,0 \times 10^{5}$ cels. $\mathrm{mL}^{-1}$, os resultados constituíram-se base para o desenvolvimento metodológico objetivando a aplicação da imunoistoquímica no diagnóstico rápido no controle de qualidade de pescados.

Palavras-chave: Microcistina, imunoistoquímica, peixe
\end{abstract}

\footnotetext{
Abstract

The deterioration of the water quality due to aquaculture is associated with eutrophication, with bloom of cyanobacteria. Microcystis aeruginosa is distinguished as main producer of microcystins (MCs), group of hepatotoxins with tumor promoter potential. In the present work immunohistochemical method

1 Farmacêutica, mestre e doutora em Ciências de Alimentos, pela Universidade Estadual de Londrina, docente de pós graduação em farmácia da UNOPAR- Universidade Norte do Paraná. E:mail: marciakamogae@londrina.net, hirooka@uel.br

2 ESALQ-USP, Universidade de São Paulo

3 Kagawa University, Kagawa, JP

4 National of Health Science, Tokyo, JP

5 Science University of Tokyo, JP

${ }^{6}$ Laboratory of Environmental Sciences, Faculty of Pharmacy, Meijo University, Nagoya, JP
}

* Autor para correspondência 
for detection of MC in tilápia (Oreochromis niloticus), fish submitted to intraperitoneal injection (i.p.) or immersion in extract of M. aeruginosa BCCBUSP 262 was developed, using monoclonal antibody anti$\mathrm{MC}(\mathrm{M} 8 \mathrm{H} 5)$ and polymer peroxidase system. The tilápias $(\mathrm{N}=42)$ had been submitted to the seven treatments, three groups inoculated i.p. with $2.0 \times 10^{5}, 4.0 \times 10^{5}$ and $1.0 \times 10^{6}$ cells. $\mathrm{Kg}^{-1}$ of M. aeruginosa BCCBUSP 262 and four groups exposed to the immersion in different extract concentrations of cyanobacterium. Analyzing liver and muscular tissue for immunohistochemical assay, muscular tissue was not stained. All the animals inoculated i.p. presented positive marking for MC in the liver, but in immersion test, only the ones exposed in the highest dose $\left(1,0 \times 10^{5}\right.$ cels. $\left.\mathrm{mL}^{-1}\right)$ presented positive marking. Although MC was not detected in muscular tissue, as well as in the liver of animals immersed in extract of M. aeruginosa BCCBUSP 262 in concentrations less than $1.0 \times 10^{5}$ cels. $\mathrm{mL}^{-1}$, the results would constitute in the base for the methodological development aiming the application of the immunohistochemistry in the rapid diagnosis in quality control of fish.

Key words: Microcystin, immunohistochemistry, fish

\section{Introdução}

Microcistinas (MCs) são hepatotoxinas produzidas por cianobactérias pertencentes aos gêneros Microcystis, Anabaena, Nostoc e Oscillatoria, cuja liberação decorre da proliferação exagerada de células e ruptura de sua parede celular em lagos e reservatórios de água doce em processo de eutrofização (CARMICHAEL, 1996).

Com atividade hepatotóxica e potencial promotor de tumor, MCs têm causado morte e doença severa em animais domésticos e selvagens, incluindo gado, pássaro e peixe (FRAZIER et al.., 1998). A toxicidade em humanos foi evidenciada em acidente envolvendo clínica de hemodiálise em CaruaruPernambuco, onde 130 pacientes renais crônicos desenvolveram insuficiência hepática aguda e 76 foram a óbito (JOCHIMSEN et al., 1998), assim como existe provável correlação entre $\mathrm{MC}$ em água de consumo e câncer hepático primário em área endêmica na China (UENO et al., 1996).

Uma única injeção de microcistina-LR (MCLR), considerada uma das mais tóxicas, produz hemorragia e necrose coagulativa no fígado e embolia em hepatócito (HOOSER et al., 1991; YOSHIDA et al., 1997). A toxicidade em animais difere conforme relatos de investigação em codorna, onde observouse aumento do baço e necrose hemorrágica em moela, intestino e tecido subcutâneo (TAKAHASHI; KAYA, 1993) e peixe (MATSUSHIMA et al., 1990; PHILIPS et al., 1985; SUGAYA; YASUNO; YANAI, 1990). A toxidez em peixe imerso em água contaminada por MC dependeu da concentração e idade/espécie animal, sendo que a dieta forçada com MC causou necrose hepática maciça e morte (SIVONEN et al., 1990).

A bioacumulação de MCs é fenômeno comum em vertebrados e invertebrados aquáticos, incluindo peixe (CARBIS et al., 1997; BEATTIE et al., 1998), molusco (ERIKSSON; MERILUOTO; LINDHOLM, 1989) e zooplâncton (WATANABE; KAYA; TAKAMURA, 1992). No contexto, conseqüências para a saúde humana podem ocorrer por via indireta, através do consumo de animais previamente expostos a florações tóxicas (BEATTIE et al., 1998). Aliado a este fator, o impacto econômico devido à morte de peixe seria alarmante, já que a piscicultura vem ocupando posição de destaque no agronegócio brasileiro (RIBEIRO et al., 2000).

Os métodos instrumentais para a detecção de MCs iniciaram-se com CLAE (cromatografia líquida de alta eficiência) e detecção em UV (238 nm) com 'photodiode array'- PDA (HARADA et al., 1988; SANO et al., 1992; EDWARDS et al., 1996).

Os avanços introduziram a nanotecnologia, com as confirmações adicionais e identificação de MCs, baseadas em espectrometria de massa LC/MS/MS (KONDO; HARADA, 1996; HARADA et al., 1996). Destaca-se também o 'Matrix Assisted Laser Desorption Ionization Time of Flight' (MALDI-TOF), que embora não seja quantitativo, permite uma avaliação rápida e qualitativa de perfil peptídico produzido, indicando inclusive, a presença dos variantes de MCs (IMANISHI; HARADA, 2004). 
A necessidade de método seguro, sensível e rápido para a detecção de $\mathrm{MC}$ no meio ambiente tem sido estimulada. Na tentativa de diminuir o custo e a complexidade instrumental, introduziu-se o 'enzymelinked immunosorbent assay'-ELISA, pela facilidade na implementação (NAGATA et al., 1997). Estes autores realizaram ELISA competitivo indireto (ICELISA) utilizando anticorpo monoclonal (M8H5) com limite de detecção de $0,0050 \mu \mathrm{g} . \mathrm{L}^{-1} \mathrm{e}$, posteriormente, o ELISA-sanduíche, aumentando a sensibilidade para 0,00020 $\mu \mathrm{g} . \mathrm{L}^{-1}$ de MC (NAGATA et al. 1999).

No contexto brasileiro, o intermitente avanço no setor agropecuário / industrial alterou o ecossistema, causando rápida deterioração dos sistemas de água doce. Soma-se a esta atividade antropogênica, a criação de animais aquáticos (piscicultura) como novo agronegócio em expansão, implicando na urgência da implantação de metodologia para controle do pescado. Entre os métodos para a detecção direta de contaminação nos tecidos, a imunoistoquímica figura como alternativa que alia sensibilidade e especificidade de anticorpos à estrutura histológica de tecido animal.

O trabalho objetiva o desenvolvimento de método imunoistoquímico para $\mathrm{MC}$ em órgão alvo de tilápia (Oreochromis niloticus), visando um instrumento eficiente para o controle de qualidade de pescado.

\section{Materiais e Métodos}

\section{Preparação de MC bruta para inoculação}

Uma alíquota de $200 \mathrm{mg}$ de floração liofilizada (coletada na estação de piscicultura da Universidade Estadual de Londrina, fevereiro / 2001) foi adicionada em 20 mL de PBS (solução tampão de fosfato) a pH 7,3 e submetida a 8 ciclos de congelamentodescongelamento seguido de $30 \mathrm{~min}$ de sonificação a $4^{\circ} \mathrm{C}$ para rompimento celular. $\mathrm{O}$ sobrenadante foi centrifugado $\left(8,31 \mathrm{x} \mathrm{g}, 15 \mathrm{~min}\right.$ a $\left.4^{\circ} \mathrm{C}\right)$, filtrado (Millipore, $45 \mu \mathrm{m}$ ) e após a quantificação de MC por IC-ELISA (NAGATA et al., 1997), o extrato foi liofilizado. MC em extrato bruto foi ressuspendida em PBS a pH 7,3 e injetado intraperitonealmente (i.p.) em peixe.

O ensaio de imersão foi executado com $M$. aeruginosa BCCBUSP 262 isolado do Lago das Garças - São Paulo, Brasil e cultivado no meio BG11 a $21-24^{\circ} \mathrm{C}$ com $14: 10$ horas de fotoperíodo luzescuro, $30-40 \mu \mathrm{mol} \cdot \mathrm{m}^{-2} \cdot \mathrm{s}^{-1}$ por 2 a 3 meses. Posteriormente, as células foram rompidas através de 8 ciclos de congelamento-descongelamento seguidos de 30 min de sonificação a temperatura ambiente.

\section{Inoculação intraperitoneal}

Tilápia do Nilo (Oreochromis niloticus), macho de seis meses $(410,2$ a $595,1 \mathrm{~g})$, cultivado na Universidade Estadual de Londrina - PR, foi anestesiado com benzocaína (1:10.000) e injetado i.p. com $2 \mathrm{mg} . \mathrm{Kg}^{-1}$ de MC (quantificada por IC-ELISA). Esta dose foi selecionada procedendo a injeção i.p. prévia em seis tilápias machos $(225,5$ a 342,2g) com 6 a $8 \mathrm{~mL}$ de floração contendo 250,0 a 1000,0 $\mu \mathrm{g} \cdot \mathrm{mL}^{-1}$ de MC. Após a morte natural do animal, o fígado foi retirado e fixado em formalina tamponada $10 \%$. O controle negativo consistiu de seis peixes eutanasiados, cujo fígado, rim e músculo foram fixados em formalina tamponada $10 \%$ por 18 horas e foram submetidos a análises histológica e imunoistoquímica.

Peixes em tanques de imersão contaminados com $\mathrm{MCs}$

Os peixes $(\mathrm{N}=42)$ foram submetidos a sete tratamentos ( 6 peixes alocados em cada tanque de 500L). Três grupos foram inoculados i.p. em dose única com concentração equivalente a $2,0 \times 10^{5}$, $4,0 \times 10^{5}$ e $1,0 \times 10^{6}$ cels. $\mathrm{Kg}^{-1}$ de $M$. aeruginosa CCBUSP 262, sendo sacrificados após 72h. Quatro grupos foram expostos por imersão: dois grupos imersos por $72 \mathrm{~h}$ em concentração equivalente de $1,0 \times 10^{4}$ e $1,0 \times 10^{5}$ cels.mL ${ }^{-1}$. A concentração celular foi determinada por contagem de células em câmara de Fuchs-Rosenthal. Dois grupos foram imersos em 
concentrações sucessivas, i.e. exposição contínua por $72 \mathrm{~h}$ e após intervalos de 2 meses procedeu-se nova exposição: um grupo imerso 2 vezes na concentração de $1,0 \times 10^{4}$ cels. $\mathrm{mL}^{-1}$ e o outro imerso 2 vezes em $1,0 \times 10^{4}$ cels. $\mathrm{mL}^{-1}$ seguida de terceira exposição $\left(2,0 \times 10^{4}\right.$ cels. $\left.\mathrm{mL}^{-1}\right)$. Após a exposição, coletou-se o fígado e tecido muscular, sendo estes imediatamente fixados em formalina tamponada $10 \%$ para a realização das análises imunoistoquímicas.

\section{Padronização de ensaio imunoistoquímico}

$\mathrm{O}$ anticorpo monoclonal primário utilizado no ensaio consistiu de sobrenadante do cultivo de hibridoma M8H5 (NAGATA et al., 1995).

A MC foi analisada por imunoistoquímica no fígado, rim e músculo de peixe. Secções $(5 \mathrm{~mm})$ embebidas em parafina, obtidos de animais inoculados e o controle negativo foram aderidos em lâminas de vidro cobertas com $5 \%$ de acetato poli-L-lisina, desparafinada em xilol, e re-hidratadas em etanol em concentrações descrecentes (100, 90 e 80\%). Peroxidase endógena foi bloqueada com solução de peroxidase $\left(\mathrm{H}_{2} \mathrm{O}_{2}+\right.$ metanol, $\left.5 \mathrm{~min}\right)$ e lavada com PBS ( $\mathrm{pH} 7,2)$. O anticorpo monoclonal (M8H5) diluído em PBS (1:100) foi adicionado e incubado (30 min). Anticorpo não ligado foi removido com tampão PBS (pH 7,2) e a lâmina incubada com anticorpo secundário - sistema polímero-peroxidase (DAKO ENVISION SYSTEM) em diluições de $(1: 1000 ; 1: 100$ e $1: 10)$ ou sistema avidina-biotinaperoxidase (VECSTAIN, VECTOR LABORATORIES) nas diluições de (1:1000; 1:100 e 1:10) por 30 min. A lâmina foi lavada e incubada por 5 min em solução de $\mathrm{H}_{2} \mathrm{O}_{2}$ e 3,3'- tetrahidroclorido diaminobenzidina (diidratado) (DAB-substrato system, Sigma, USA), novamente lavada com água destilada e contra-corada com hematoxilina de Mayer e montada com resina sintética.

\section{Deteç̧ão de MCs}

MC total em floração foi determinado por IC-ELISA (NAGATA et al., 1997). Para identificação de MC procedeu-se CLAE com detector PDA (238 nm) e MALDI-TOF (IMANISHI; HARADA, 2004).

IC-ELISA para deteç̧ão de MCs total (NAGATA et al., 1997)

MC total foi analisado por IC-ELISA utilizando MC-LR com 95\% de pureza, MC-LR conjugada com soroalbumina bovina (MCLR-BSA) e anticorpo monoclonal M8H5 (NAGATA et al., 1997). A microplaca foi sensibilizada com MCLR-BSA, e adicionada das amostras misturadas com anticorpo monoclonal M8H5. Após incubação 'overnight', foi adicionado o IgG-peroxidase (1:5000 em PBS-Tween com $0,5 \%$ gelatina) e novamente incubado, adicionado com 3,3'-5,5'tetrametil benzidina- TMBZ e lido a 450 nm. O limite de quantificação foi de $0,0050 \mu \mathrm{g} \cdot \mathrm{L}^{-1}$.

Análise de MC em floração por CLAE e MALDITOF/MS - 'Matrix assisted laser desorption/ ionisation-time of flight mass spectrometry'

Floração liofilizada foi extraída com 5\% de ácido acético, centrifugada e o sobrenadante aplicado sobre cartucho de ODS - octadecyl silanizado (BAKER, PHILLIPSBURGH, NJ, EUA) para limpeza, e o eluato seco. Para CLAE utilizou-se o detector diode array $(238 \mathrm{~nm})$ e coluna 5C18-AR de Cosmosil sob condição isocrática (HARADA et al., 1997). Procedeu-se a análise de MALDI-TOF/MS com amostra tratada com solução matriz cristalizada de ácido $\alpha$-cyano-4hidroxi-cinnamic (CHCA) e analisada por espectrômetro de massa (APPLIES BIOSYSTEMS VOYAGER DE-PRO, FRAMINGHAN, MA, EUA).

\section{Resultados e Discussão}

Para o desenvolvimento metodológico, o fígado, rim e músculo de tilápia (Oreochromis niloticus) macho e adulto, inoculados i.p.com extrato bruto de floração contendo aproximadamente $2 \mathrm{mg} \cdot \mathrm{Kg}^{-1}$ de MCs foram submetidos ao ensaio imunoistoquímico, 
constituindo o controle positivo da metodologia. A dose i.p. letal necessária para o estudo imunoistoquímico foi selecionada baseada em estudo preliminar em tilápia, procedendo inoculação i.p. de floração natural com predominância de Microcystis spp. A dose i.p. variou de 250 a $1000 \mathrm{mg} . \mathrm{Kg}^{-1} \mathrm{de}$
MC, em volumes de 6 a $8 \mathrm{~mL}$. Embora IC-ELISA determine MCs totais, a CLAE (Figura 1) demonstrou um pico correspondente a MC-LR no inóculo, caracterizada pela elevada toxicidade entre as MCs. Após morte do animal, o fígado, rim e músculo foram analisados por imunoistoquímica.

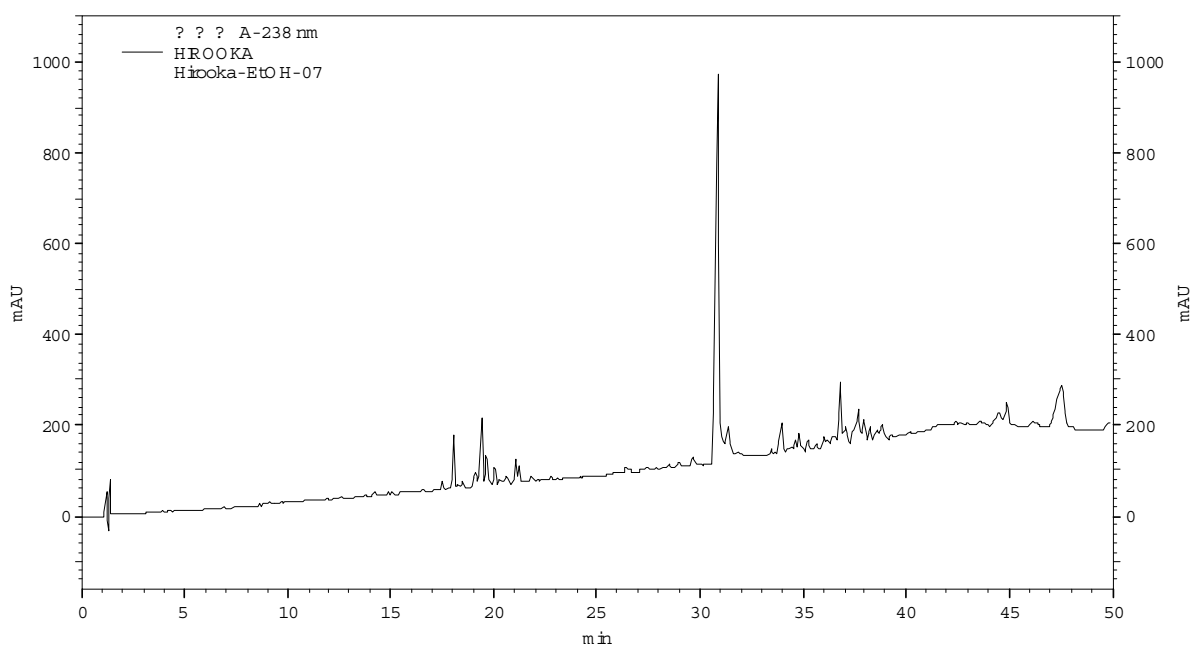

Figura 1. Perfil cromatográfico de floração de Microcystis spp. por Cromatografia Líquida de Alta Eficiência (CLAE), apresentando pico em 31 minutos, referente ao de MC-LR.

A preparação de corte histológico de tecido envolveu fixação por $18 \mathrm{~h}$ em formalina tamponada $10 \%$, para preservar a morfologia tecidual e mostrar a reação anticorpo-MC. Após a fixação, a Tabela 1 mostra que melhores resultados foram obtidos com anticorpo monoclonal anti-MC diluídos a 1:10 e 1:100 em PBS 0,01M ( $\mathrm{pH} 7,2)$ empregando sistema polímero-peroxidase, não apresentando diferenças significativas entre as diluições, sendo portanto, a diluição 1:100 selecionada para análise imunoistoquímica posterior.

Tabela 1. Comparação entre técnica imunoistoquímica utilizando avidina-biotina-peroxidase e sistema polímeroperoxidase.

\begin{tabular}{lcl}
\hline Sistema imunoistoquímico & Diluição do anticorpo monoclonal & Reatividade \\
\hline AVIDINA-BIOTINA- & $1: 1000$ & NEGATIVO \\
PEROXIDADE & $1: 100$ & NEGATIVO \\
& $1: 10$ & NEGATIVO \\
\hline \multirow{2}{*}{ POLÍMERO-PEROXIDASE } & $1: 1000$ & NEGATIVO \\
& $1: 100$ & POSITIVO \\
& $1: 10$ & POSITIVO \\
\hline
\end{tabular}


Analisando os cortes obtidos de fígado, rim e músculo por imunoistoquímica, apenas o fígado de animais submetidos à injeção i.p., assim como de animais expostos a imersão em tanque contaminado com dose-extrato de $1,0 \times 10^{5}$ cels. $\mathrm{mL}^{-1}$ de $M$. aeruginosa CCBUSP 262 apresentaram-se positivos, sugerindo a especificidade de $\mathrm{MC}$ por este órgão (Tabela 2).

Conforme literatura, MCs apresentaram organotropia única pelo fígado, com administração i.p. e oral em ratos e camundongos, causando hemorragia intra-hepática massiva e necrose celular dentro de poucas horas (BEASLEY et al., 1989; DAWSON, 1998; TENCALLA; DIETRICH, 1997). No entanto, esta organotropia não se repetiu em codorna, que apresentaram perfil tóxico diferente, com o comprometimento de baço, mas sem alteração hepática (TAKAHASHI; KAYA, 1993). Em nosso experimento, com tilápia, a MC apresentou afinidade pelo fígado (Tabela 2, Figura 2).

Tabela 2. Marcação imunoistoquímica em tecido de tilápia (Oreochromis niloticus), após exposição a tratamentos de imersão ou injeção intraperitoneal.

\begin{tabular}{|c|c|c|c|}
\hline \multirow[t]{2}{*}{ TRATAMENTO } & \multicolumn{3}{|c|}{ TECIDO } \\
\hline & HEPÁTICO & RENAL & MUSCULAR \\
\hline $2,0 \times 10^{5}$ cel. $\mathrm{Kg}^{-1}$ & + & - & - \\
\hline $4,0 \times 10^{5}$ cel. $\mathrm{Kg}^{-1}$ & + & - & - \\
\hline $1,0 \times 10^{6} \mathrm{cel} \cdot \mathrm{Kg}^{-1}$ & + & - & - \\
\hline $1,0 \times 10^{4}$ cel. $\mathrm{Kg}^{-1}$ & - & - & - \\
\hline $1,0 \times 10^{5} \mathrm{cel} \cdot \mathrm{Kg}^{-1}$ & + & - & - \\
\hline $2 \times 1,0 \times 10^{4}$ cel. $\mathrm{Kg}^{-1}$ & - & - & - \\
\hline $2 \times 1,0 \times 10^{4}$ cel. $\mathrm{Kg}^{-1} 1 \times 2,0 \times 10^{4}$ cel. $\mathrm{Kg}^{-1}$ & - & - & - \\
\hline
\end{tabular}

Marcação imunoistoquímica: positivo (+), negativo (-).

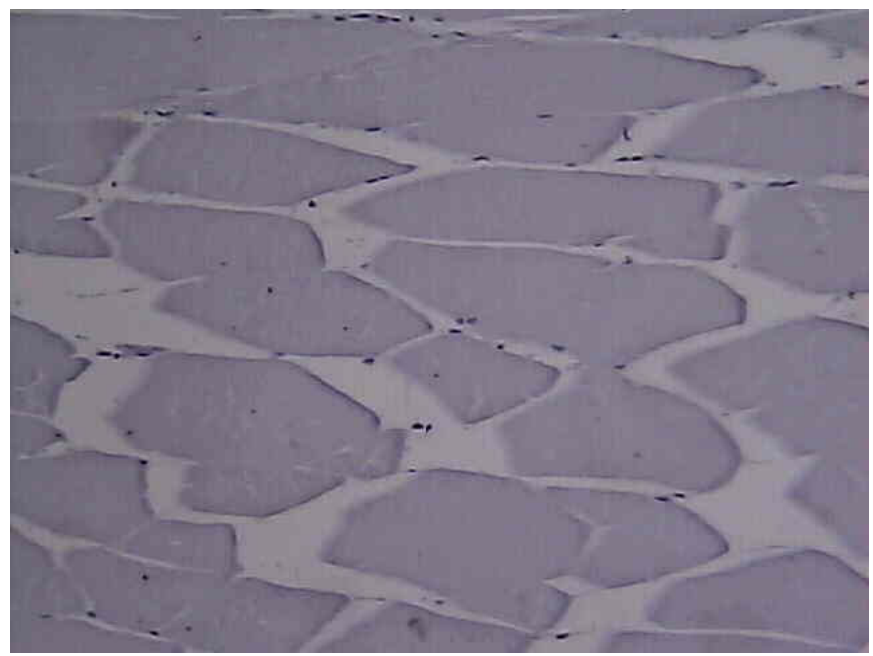

Figura 2. Tecido muscular de Tilápia (Oreochromis niloticus) exposto a extrato de Microcystis aeruginosa BCCUSP 262. Marcação imunoistoquímica negativa para microcistina, aumento de 200X. 
A reação negativa no rim indicou a possibilidade de não-excreção destas substâncias através desta via, ou a metabolização inicial de MC no fígado assim como a sua permanência neste órgão, onde predomina efeito tóxico.

A reação negativa para $\mathrm{MC}$ no músculo sugeriu que a exposição aguda não permitiu o acúmulo em tecido muscular, porém isto não comprova se a exposição crônica seguiria o mesmo perfil de contaminação tecidual (Figura 2).

Segundo Magalhães, Soares e Azevedo (2001), a exposição crônica de peixe a MC através da ingestão natural de cianobactérias na represa de Jacarepaguá - Rio de Janeiro - Brasil, possibilitou a detecção de MCs no músculo, indicando efeito residual de MCs neste tecido muscular. Outrossim, cuidados na interpretação em relação a técnica imunoquímica utilizada no ensaio por Magalhães, Soares e Azevedo (2001) torna-se essencial, devido ao alto risco de falso-positivo em substrato biológico. Os resultados de imunoistoquímica em fígado de peixe inoculado com MCs apresentaram-se positivos, com marcação reativa de antígeno-anticorpo difusamente nos hepatócitos, demonstrando especificidade (Figuras 3A e 3B). No detalhe do corte, pode-se observar a marcação apenas do citoplasma do hepatócito (marcado em castanho), com núcleo e nucléolo bem definidos (característica normal de hepatócito) e não corados, enquanto que no tecido pancreático não ocorreu marcação reativa (azul). No corte histológico observaram-se alguns pontos isolados de necrose, mas sem apoptose. O espaço sinusóide não apresentou nenhum tipo de alteração, indicando que não ocorreu extravasamento intracelular de conteúdo hepático.
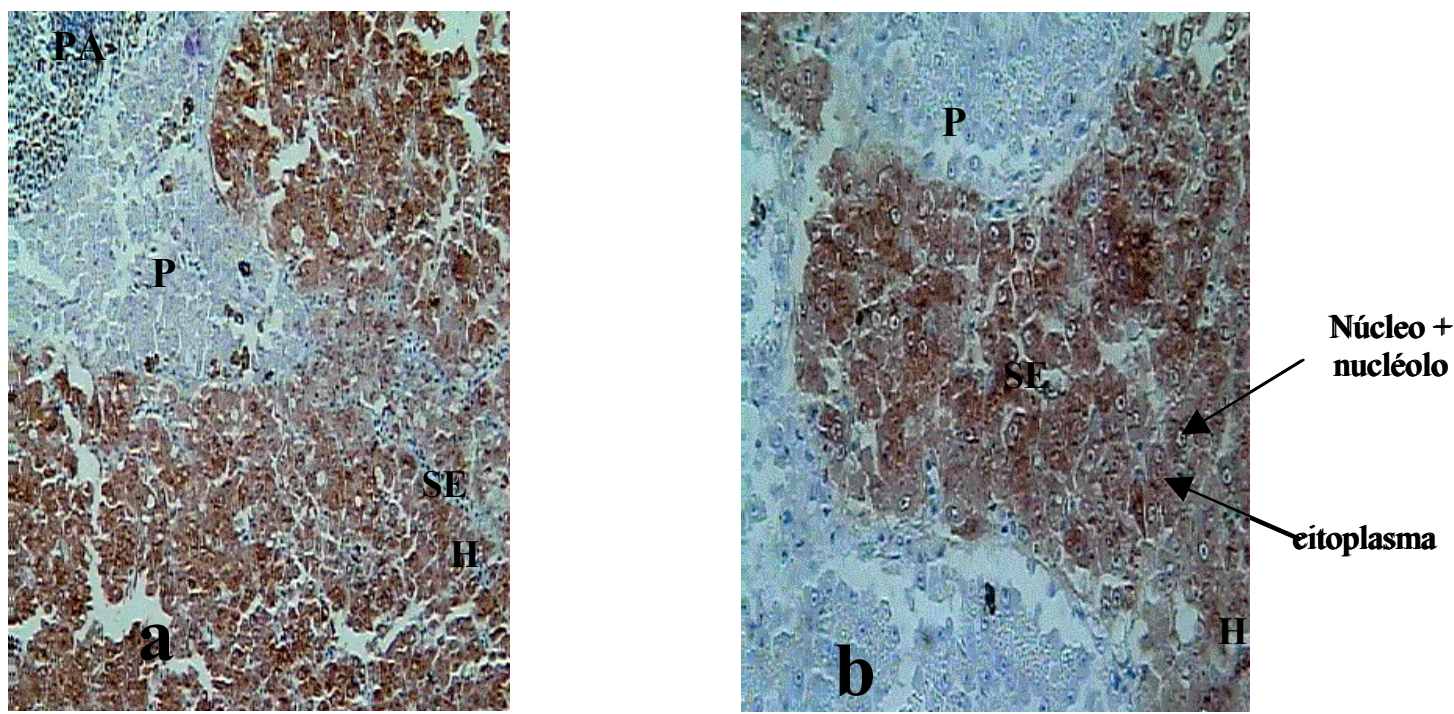

Figura 3. Marcação imunoistoquímica de fígado de tilápia (Oreochromis niloticus) inoculado com microcistina-LR (MC-LR). Reação positiva MC-LR (marrom). a) X 200 b) X 400. P=pâncreas, PA= área portal, SE= espaço sinusoidal, $\mathrm{H}=$ hepatócito

A utilização de sistema avidina-biotina-peroxidase como técnica imunoistoquímica não se mostrou eficiente para marcação reativa de $\mathrm{MC}$ em fígado de peixe, mesmo utilizando diluição do anticorpo monoclonal 1:10, conforme demonstrado na Tabela 1. Não obstante, a marcação imunoistoquímica com o sistema polímero-peroxidade (DAKO ENVISION
PEROXIDADE) apresentou-se como recurso viável, apresentando vantagens como redução no tempo de análise de 24 para 12 horas de ensaio, reduzindo uma etapa de incubação 'overnight' e permitindo visualização adequada de complexo antígenoanticorpo formado. Embora não seja um reagente de baixo custo, quando comparado com outros kits 
para imunoistoquímica disponíveis no mercado, apresenta-se bastante competitivo. A redução no tempo de análise, bem como a facilidade do emprego desta técnica em laboratório, tornaria possível a utilização de imunoistoquímica entre ferramentas de identificação de MC em fígado de peixe.

Embora MC não tenha sido detectada em tecido muscular, assim como em fígado dos animais imersos em extrato de $M$. aeruginosa diluído em doses inferiores a $1,0 \times 10^{5}$ cels. $\mathrm{mL}^{-1}$, os resultados constituíram a base para o desenvolvimento metodológico objetivando futura aplicação de imunoistoquímica no diagnóstico rápido no controle de qualidade de pescado.

\section{Agradecimentos}

À Estação de Piscicultura CCB/UEL e seus responsáveis técnicos Heitor Frossard e Mauro Caetano Filho, pelo espaço físico e animais experimentais; ao CNPq e CAPES, pela concessão de bolsas de estudo e financiamento do projeto de pesquisa.

\section{Referências}

BEASLEY, V.R.; COOK, W.O.; DAHLEM, A.M.; HOOSER, S.B.; LOVELL, R.A.; VALENTINE, W.M. Algae intoxication in livestock and waterfowl. The Veterinary Clinics of North America: Food Animal Practice, Philadelpia, v.5, n.2, p.345-361, 1989.

BEATTIE, K.A.; KAYA, K.; SANO, T.; CODD, G. Three dehydrobutyrine (Dhb)-containing microcystins from the cyanobacterium Nostoc sp. Phytochemistry, Oxford, v.47, n.7,p.1289-1292, 1998.

CARBIS, C.R.; RAWLIN, G.T.; GRANT, P.; MITCHELL, G.F.; ANDERSON, J.W.; MacCAULEY. A study of feral carp Cyprinus carpio L., exposed to Microcystis aeruginosa at Lake Mokoan, Australia, and possible implication on fish health. Journal of Fish Diseases, Oxford, v.20, n.2, p.81-91, 1997.

CARMICHAEL, W.W. Toxic Microcystis and environment. In.: WATANABE, M.; HARADA, K.; CARMICHAEL, W.W.; FUJIKI, H. (Ed.). Toxic Microcystis. Boca Raton: CRC Press. p.1-11, 1996.
DAWSON, R.M. The toxicology of microcystins. Toxicon, Oxford, v.36, n.7, p.953-962, 1998.

EDWARDS, C.; LAWTON, L.A.; COYLE, S.M.; ROSS, P. Laboratory-scale purification of microcystins using flash chromatography and reversed-phase high-performance liquid chromatography. Journal of Chromatography A, Amsterdam, v.734, n.1, p.163-173, 1996.

ERIKSSON, J.E.; MERILUOTO, J.A.; LINDHOLM, T. Accumulation of peptide toxin from the cyanobacterium Oscillatoria agardhi in the fresh water mussel Anadonta cygnea. Hydrobiologia, Den Haag, v.183, p.211-216, 1989.

FRAZIER, K.; COLVIN, B.; STYER, E.; HULLINGER, G.; GARCIA, R. Microcystin toxicosis in cattle due to overgrowth of blue-green algae. Veterinary and Human Toxicology, Manhattan, v.40, n.1, p.23-24, 1998.

HARADA, K.; SUZUKI, M.; DAHLEM, A.M.; BEASLEY, V.R.; CARMICHAEL, W.W.; RINEHART, K.L. Improved methods for purification of toxic peptides produced by cyanobacteria. Toxicon, Oxford, v.26, n.5, p.433-439, 1988.

HARADA, K.; MURATA, H.; QIANG, Z.; SUZUKI, M.; KONDO, F. Mass spectrometric screening method for microcystins in cyanobacteria. Toxicon, Oxford, v.34, n.6, p.701-710, 1996.

HARADA, K.; OSHIKATA, M.; SHIMADA, T.; NAGATA, A.; ISHIKAWA, N.; SUZUKI, M.; KONDO, F.; SHIMIZU, M.; YAMADA, S. High-performance liquid chromatographic separation of microcystins derivatized with a highly fluorescent dienophile. Natural Toxins, New York, v.5, n.5, p.201-207, 1997.

HOOSER, S.B.; BEASLEY, V.R.; WAIT, L.L.; KUKLESCHIMIDT, M.S.; CARMICHAEL, W.W.; HASCHEK, W.N. Actin filament alterations in rat hepatocytes induced in vivo and in vitro by microcystinLR, a hepatotoxin the blue-green algae Microcystis aeruginosa. Veterinary Pathology, New York, v.28, p.259266, 1991.

IMANISHI, S.; HARADA, K. Proteomics approach on microcystin binding proteins in mouse liver for investigation of microcystin toxicity. Toxicon, Oxford, v.43, n.6, p.651-659, 2004.

JOCHIMSEN, E.M.; CARMICHAEL, W.W.; AN, J.; CARDO, D.; COOKSON, S.T.; HOLMES, C.E.M.; ANTUNES, M.B.C.; MELO FILHO, D.A.; LYRA, T.M.; BARRETO, V.; AZEVEDO, S.M.F.O; JARVIS, W.R. Liver failure and death following exposure to microcystin toxins at a hemodialysis center in Brazil. The New England Journal of Medicine, Boston, v.338, n.13, p.873-878, 1998.

KONDO, F.; HARADA, K. Mass spectrometric analyses of cyanobacterial toxins. Journal of the Mass Spectrometry Society of Japan, v.44, n.3, p.355-376, 1996. 
MAGALHÃES, V.F.; SOARES, R.M.; AZEVEDO, S.M.F.O. Microcystin contamination in fish from the Jacarepaguá Lagoon (Rio de Janeiro, Brasil): ecological implication and human health risk. Toxicon, Oxford, v.39, n.7, p.1077-1085, 2001.

MATSUSHIMA, R,; YOSHIZAWA, S.; WATANABE, M.F.; HARADA, K.; FURUSAWA, M.; CARMICHAEL, W.W.; FUJIKI, H. In vitro and in vivo effects of protein phosphatase inhibitors, microcystins and nodularin, on mouse skin and fibroblasts. Biochemical and Biophysical Research Communications, New York, v.171, n.2, p.867$874,1990$.

NAGATA, S.; SOUTOME, H.; TSUTSUMI, T.; HASEGAWA, A.; SEKIJIMA, M.; SUGAMATA, M.; HARADA, K.; SUGANUMA, M.; UENO, Y. Novel monoclonal antibodies against microcystin and their protective activity for hepatotoxicity. Natural Toxins, New York, v.3, n.2, p.78-86, 1995.

NAGATA, S., TSUTSUMI, T., HASEGAWA, A., YOSHIDA, F., UENO, Y.; WATANABE, M.F. Enzyme immunoassay for direct determination of microcystins in environmental water. Journal of AOAC International, Arlington, v.80, n.2, p.408-417, 1997.

NAGATA, S.; TSUTSUMI, T.; YOSHIDA, F.; UENO, Y. A new type sandwich immunoassay for microcystin: production of monoclonal antibodies specific to the immune complex formed by microcystin and antimicrocystin monoclonal antibody. Natural Toxins, New York, v.7, n.2, p.49-55, 1999.

PHILIPS, M.J.; ROBERTS, R.J.; STEWART, J.A.; CODD, G.A., The toxicity of the cyanobacterium Microcystis aeruginosa to rainbow trout, Salmo gairdneri Richardson. Journal of Fish Diseases, Oxford, v.8, n.4, p.339-344, 1985.

RIBEIRO, L.P.; MIRANDA, M.O.T.; LIMA, L.C.; HOLANDA, E.D. Aquacultura empresarial. Informe Agropecuário, Belo Horizonte, v.21, n.203, p.5-9, 2000.

SANO, T.; NOHARA, K.; SHIRAISHI, F.; KAYA, K. A method for micro-determination of total microcystin content in waterblooms of cyanobacteria (blue-green algae). International Journal of Environmental Analytical Chemistry, New York, v.49, n.3, p.163-170, 1992.
SIVONEN, K.; CARMICHAEL, W.W.; NAMIKOSHI, M.; RINEHART, K.L.; DAHLEM, A.M.; NIEMELA, S.I. Isolation and characterization of hepatotoxic microcystin homologs from the filamentous freshwater cyanobacterium Nostoc sp strain 152. Applied and Environmental Microbiology, Washington, v.56, n.9, p.2650-2657, 1990.

SUGAYA, Y.; YASUNO, M.; YANAI, T. Effect of toxic Microcystis viridis and isolated toxins on goldfish. Japanese Journal of Limnology, Tokyo, v.51, n.3, p.149$153,1990$.

TAKAHASHI, S.; KAYA, K. Quail spleen is enlarged by microcystin RR as a blue-green algal hepatotoxin. Natural Toxins, New York, v.1, n.5, p.283-285, 1993.

TENCALLA, F.; DIETRICH, D. Biochemical characterization of microcystin toxicity in rainbow trout (Oncorhynchus mykiss). Toxicon, Oxford, v.35, n.4, p.583$595,1997$.

UENO, Y.; NAGATA, S.; TSUTSUMI, T.; HASEGAWA, A.; WATANABE, M.F.; PARK, H.D.; CHEN, G.C.; CHEN, G.; YU, S.Z. Detection of microcystins, a blue-green algal hepatotoxin, in drinking water sampled in Haimen and Fusui, endemic areas of primary liver cancer in China, by highly sensitive immunoassay. Carcinogenesis, New York, v.17, n.6, p.1317-1321, 1996.

WATANABE, M.M.; KAYA, K.; TAKAMURA, N. Fate of the toxic cyclic heptapeptides, the microcystins, from blooms of Microcystis (cyanobacteria) in a hypertrophic lake. Journal of Phycology, New York, v.28, n.6, p.761$767,1992$.

YOSHIDA, T.; MAKITA, Y.; NAGATA, S.; TSUTSUMI, T.; YOSHIDA, F.; SEKIJIMA, M.; TAMURA, S.; UENO, Y. Acute oral toxicity of microcystin-LR, a cyanobacterial hepatotoxin, in mice. Natural Toxins, New York, v.5, n.3:91$95,1997$. 
